\title{
ARTIGO
}

\section{DESENVOLVIMENTO DE METODOLOGIA EXPERIMENTAL PARA AVALIAÇÃO DE ATENUAÇÃO DE RUÍDO ESTRUTURAL ATRAVÉS DE ABSORÇÃO SONORA EM AUTOMÓVEIS ${ }^{1}$}

\author{
Rogério Gondim Costa ${ }^{2}$ \\ Claysson Bruno Santos Vimieiro \\ Tiago Simão Ferreira
}

\begin{abstract}
RESUMO
Este trabalho aborda o desenvolvimento de uma metodologia para avaliar a atenuação do ruído transmitido por via estrutural ao habitáculo de um automóvel através da aplicação de material para absorção sonora. As soluções para os ruídos transmitidos por via estrutural são, geralmente, mais complexas para implementação e demandam maior tempo e custo, uma vez que possuem diversos vínculos com outros quesitos de desempenho do veículo, pois estão relacionadas às modificações que podem contemplar a estrutura, suportes ou coxins. Os materiais para absorção sonora são utilizados em automóveis com o objetivo de atenuar ruídos de alta frequência, devido às suas características. Este estudo propõe a utilização desse tipo de material para atenuar ruídos de baixas e médias frequências, predominantes em ruído estrutural, complementando os existentes, de modo a refinar o comportamento vibroacústico do veículo. Para o desenvolvimento da metodologia foi construído um protótipo de habitáculo de um automóvel em aço e realizados testes de Função de Resposta em Frequência vibroacústica. Para validação da metodologia foram realizados testes com e sem mantas de absorção sonora. Observou-se nos testes realizados que a aplicação de material de absorção sonora atenua de forma significativa o ruído estrutural na faixa de médias frequências e que a metodologia desenvolvida pode auxiliar no desenvolvimento de novas propostas, testes comparativos de materiais, posicionamentos e região de aplicação das mantas. Isso contribui na redução de tempo de desenvolvimento de soluções de propostas para refinamento do conforto acústico em veículos.
\end{abstract}

Palavras-chave: Ruído estrutural. Conforto acústico. Absorção sonora. FRF.

\section{INTRODUÇÃo}

O conforto vibroacústico em veículos possui grande importância na composição da qualidade global e tornou-se uma exigência dos clientes. Essa demanda faz com que os fabricantes de veículos e fabricantes de componentes automotivos estejam empenhados em buscar soluções mais eficazes a cada dia, para garantir a boa qualidade de seus produtos (WANG, 2010).

Devido às diversas fontes de ruídos e vibrações que estão presentes nos veículos e às condições dinâmicas nas quais os veículos são expostos, as soluções de problemas relacionados aos ruídos e vibrações tornam-se complexas por apresentarem amplas faixas de frequências e combinação de formas de transmissão. Os fabricantes de veículos têm investido em pesquisas que buscam a solução de problemas relacionados aos ruídos e vibrações que contemplem menor

\footnotetext{
${ }^{1}$ Como citar este artigo: COSTA, Rogério Gondim; VIMIEIRO, Claysson Bruno Santos; FERREIRA, Tiago Simão. Desenvolvimento de tecnologia experimental para avaliação de atenuação de ruído estrutural através de absorção sonora em automóveis. ForScience: revista científica do IFMG, Formiga, v. 6, n. 3, e00444, jul./dez. 2018. DOI: 10.29069/forscience.2018v6n3.e00444.
}

${ }^{2}$ Autor para correspondência: Rogério Gondim Costa, Faculdade Pitágoras, e-mail: rogeriogondim@gmail.com 
tempo de desenvolvimento, menor custo e que assegure a boa qualidade. Portanto, o bom conhecimento das formas de geração e de transmissão do ruído ao habitáculo é de fundamental importância.

O ruído pode ser transmitido ao interior do veículo através do ar (ruído aéreo) e através da estrutura (ruído estrutural). O ruído estrutural é originado das vibrações que a estrutura recebe, propaga por toda a carroceria e a vibração dos painéis gera o ruído na cavidade interna do veículo. O ruído estrutural é percebido em frequências até $600 \mathrm{~Hz}$, enquanto que o ruído aéreo pode ser percebido no intervalo de 400 a $10000 \mathrm{~Hz}$ (GOETCHIUS, 2010). O gráfico da Figura 1 demonstra a contribuição dos ruídos aéreo e estrutural por faixa de frequência.

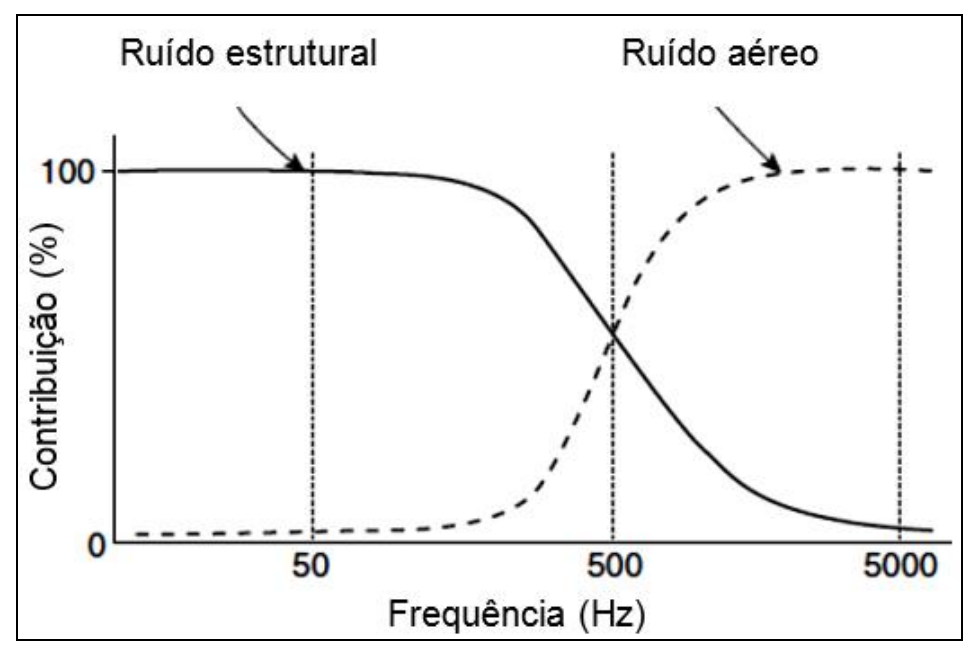

Figura 1- Contribuição de ruído estrutural e ruído aéreo no ruído global de um veículo Fonte: Goetchius (2010).

As principais fontes de ruído estrutural em um veículo são o conjunto motopropulsor e o conjunto pneus, rodas e suspensão (HARISSON, 2004).

As soluções para atenuação de ruído estrutural são mais complexas que as soluções para o ruído aéreo. O ruído aéreo geralmente é tratado através de isolamentos que possuem características de isolação e absorção, e são aplicados no pavimento, na parede corta fogo e no vão do motor, entre outros. Esses isolamentos funcionam bem para atenuação de ruído de frequências altas. Para atenuar o ruído transmitido pela estrutura, as formas mais eficazes requerem uma otimização das características vibracionais da carroceria, principalmente nos pontos de contato de sustentação das fontes vibracionais e nos suportes de sustentação ou otimização dos elementos elásticos que estão localizados entre a fonte e a estrutura, que são os coxins. Esses componentes possuem outros vínculos como, por exemplo, a carroceria tem a deformação controlada em caso de colisão, os suportes e coxins precisam sustentar os sistemas sem se romperem. Devido a esses vínculos, as propostas de soluções precisam ser submetidas a diversos estudos, o que torna o tempo de desenvolvimento longo e o custo elevado. Desta forma, problemas relacionados aos ruídos transmitidos por via estrutural em automóveis podem permanecer sem solução após o término do desenvolvimento de um produto, comprometendo a sua qualidade. 
Este trabalho tem como objetivo desenvolver uma metodologia experimental para avaliar o efeito de materiais de absorção sonora em ruídos transmitidos por via estrutural ao habitáculo de um automóvel. Para esse desenvolvimento, foi construído um protótipo de carroceria de um automóvel pequeno utilizando tubos e chapas de aço e foram realizadas medições de funções de resposta em frequência (FRF) vibroacústicas, com entrada de sinal de força na carroceria e com resposta em nível de pressão sonora (NPS) no interior do habitáculo. Para validação da metodologia, os testes de atenuação de ruído foram realizados nas condições da carroceria sem isolamentos e com isolamentos. Os isolamentos utilizados foram mantas de material poroso de fibra têxtil de aplicação automotiva.

\section{REFERENCIAL TEÓRICO}

\subsection{Conceitos de Acústica}

Acústica é a ciência que estuda a geração, transmissão e a recepção de energia em forma de ondas vibratórias (KINSLER et al, 2000). O termo som possui ampla denotação, não se refere apenas ao fenômeno da audição, mas também a perturbações em frequências muito baixas, denominadas infrassons e, em frequências elevadas, denominadas ultrassons, que não podem ser ouvidas pelo ser humano. O som é a variação da pressão ambiente que se propaga pelo ar a partir de uma fonte geradora de vibração, até atingir o ouvido. Para que esta propagação ocorra, é necessário que aconteçam compressões e rarefações em propagação do meio. Quando passa, a onda sonora não arrasta as partículas do meio, apenas faz com que estas vibrem em torno de sua posição de equilíbrio, chocando-se umas com as outras e se propagando (BISTAFA, 2011). A propagação do som se dá em forma de ondas esféricas, a partir de uma fonte pontual. Obstáculos na trajetória e/ ou não uniformidades do meio, como ventos e gradientes de temperaturas, podem alterar esse modelo simples de propagação (GERGES, 2000).

O ouvido humano pode perceber variações de pressão a partir de 0,00002 Pascal, denominado limiar da audição ou da audibilidade, até 200 Pascal, intensidade na qual o som pode ser sentido e provocar dor, denominado limiar da dor. No nível do mar, a pressão atmosférica é de 1 atmosfera (atm), que corresponde a 101325 Pascal. O sistema auditivo detectará um som quando a variação de pressão for cíclica com um determinado período e a amplitude alcançar um valor maior que o limiar da audibilidade. A variação da pressão ambiente é chamada de pressão sonora (BISTAFA, 2011).

O período de uma onda sonora é o intervalo de tempo para ocorrência de um ciclo completo na curva de variação da pressão ambiente com o tempo. O inverso do período é a frequência, que é medida em ciclos por segundo ou Hertz $(\mathrm{Hz})$ pelo Sistema Internacional de Unidades (SI) e indica o número de períodos existentes em um segundo. $\mathrm{O}$ alcance da audição humana se estende de $20 \mathrm{~Hz}$ a $20000 \mathrm{~Hz}$. Essa faixa de frequências audíveis aos seres humanos é 
chamada de faixa de áudio. Sons com frequências abaixo de $20 \mathrm{~Hz}$ são chamados de infrassons e acima de $20000 \mathrm{~Hz}$ chamados de ultrassons (BISTAFA, 2011).

Um som considerado desagradável é denominado de ruído, e o incômodo gerado dependerá de suas características como frequência, amplitude, duração e, também, de como a pessoa reage a ele (VECCI, 2004).

\subsection{Ruído Veicular}

O comportamento de veículos quanto ao ruído, vibração e aspereza (Noise Vibration Harshness $-\mathrm{NVH}$ ) determinam o conforto vibroacústico. Os automóveis possuem diversas fontes geradoras desses fenômenos que funcionam simultaneamente e variam de acordo com as condições que são submetidos, tornando esse tema bastante complexo. É necessário conhecer as fontes geradoras, suas condições de funcionamento e formas de transmissão para o habitáculo para aplicação de soluções que atenuem os níveis de ruídos e vibrações para os ocupantes do veículo.

O ruído é transmitido ao habitáculo de um veículo por vias aérea e estrutural. O ruído transmitido por via aérea é predominantemente de altas frequências. Já o ruído transmitido por via estrutural, frequências baixas e médias. O ruído transmitido pela estrutura predomina em frequências abaixo de $200 \mathrm{~Hz}$, enquanto o ruído aéreo é predominante a partir de $500 \mathrm{~Hz}$. Na faixa de médias frequências ambos os caminhos são importantes (VIGÈ, 2010).

$\mathrm{Na}$ transmissão por via aérea o ruído oriundo das fontes atinge o habitáculo através do ar e sua percepção é dependente das características dos materiais utilizados no interior do veículo. A transmissão por via estrutural ocorre devido à propagação de vibrações geradas pelas fontes através da estrutura do veículo. A energia vibratória causa vibração nos painéis, que por sua vez, estando em contato com a cavidade interna do veículo, induzem flutuações da pressão interna, que são transmitidas até o ouvido dos ocupantes (MOURA, 2016). A Figura 2 apresenta a divisão entre sistema ativo (fonte) e passivo (receptor) e formas de transmissão de ruído (estrutural e aéreo) e de vibração (estrutural).

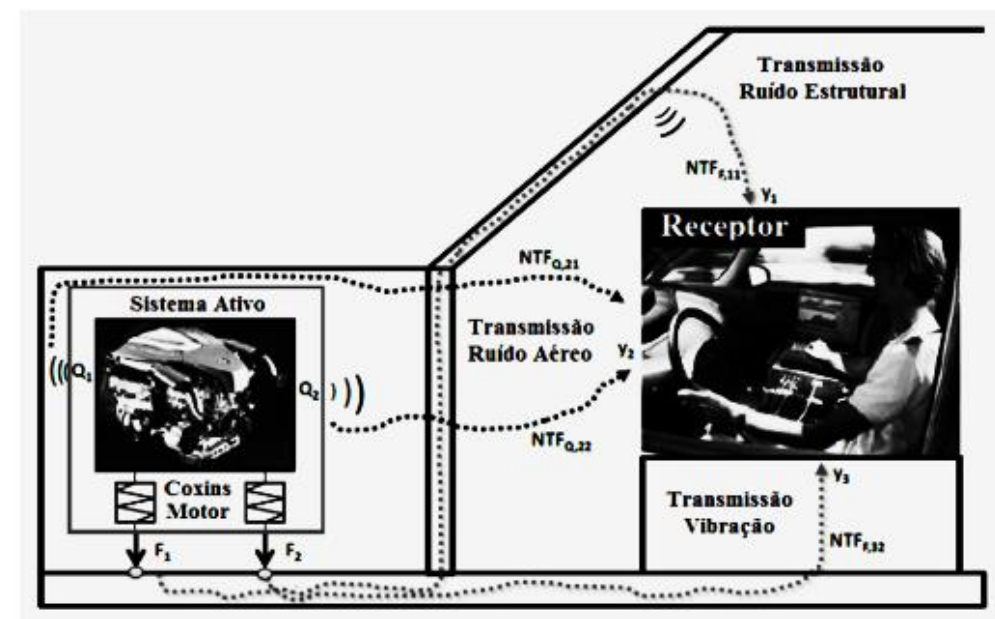

Figura 2 - Fontes e caminhos de propagação em veículo Fonte: Gajdàtsy (2011). 
O sistema de propulsão que engloba o motor, o câmbio, o escapamento e o sistema de aspiração é a principal fonte de ruídos e vibrações em um veículo. Estas fontes irradiam ruído pelo ar através de suas superfícies e gera vibrações que são transmitidas pela estrutura. Parte dessa transmissão pode se comportar como elemento irradiante para o interior do veículo, que é o caso das chapas mais planas como a parede corta fogo, assoalho e teto. No sistema de propulsão, o ruído devido à combustão dos gases é o predominante. Além deste, o motor gera ruído devido às forças mecânicas e atritos, assim como o câmbio. O sistema de escapamento gera ruído devido às flutuações de pressão no sistema causadas pelas válvulas de escape e ruído devido ao jato na saída do tubo. $\mathrm{O}$ sistema de aspiração gera ruídos devido às oscilações da coluna de gás nos dutos que são originadas da ação das válvulas de aspiração e, além deste, existe a radiação de ondas sonoras das superfícies do filtro de ar e dutos do sistema e o ruído e vibrações transmitidos por via estrutural, através dos pontos de fixação do sistema ao veículo (GERGES, 2005).

O conjunto pneus e suspensão transmitem o ruído de rolagem e é uma importante fonte, principalmente em velocidades acima de $60 \mathrm{~km} / \mathrm{h}$. O projeto do sistema que contém os pneus, as rodas, os elementos da suspensão e a fixação à carroceria influenciam de forma significativa no ruído de rolagem. Características como o tipo de pneu e de roda, pressão do pneu e tipo de suspensão determinam o comportamento acústico deste sistema. Além disso, o tipo de pavimento da estrada tem influência, como é o caso da rugosidade e das irregularidades do asfalto ou tipo de calçamento. Diferentes fenômenos contribuem simultaneamente para geração do ruído de pneus e suspensão. A principal origem do ruído de pneus é o constante golpear da superfície deste com a rugosidade do solo. As pequenas rugosidades do piso agem como obstáculos à rolagem do pneumático que se choca com essas, vindo a vibrar. Como esses choques ocorrem a curtíssimos intervalos de tempo, visto que as imperfeições do piso ocorrem a distâncias mínimas, a frequência do ruído resultante é da ordem de 500 a $1000 \mathrm{~Hz}$, dependendo da velocidade do veículo. Quanto maior a velocidade, maior a frequência (GERGES, 2005).

\subsection{Trajetórias de transferência vibroacústicas}

As trajetórias de transferência de ruído e vibração representam os caminhos pelos quais a energia vibroacústica é transmitida desde as fontes geradoras até atingir os ocupantes de um veículo, seja pela percepção da vibração ou pela percepção sonora.

Técnicas experimentais de análises de caminhos de transmissão foram desenvolvidas para caracterização de trajetórias vibroacústicas, a partir da utilização de Funções de Resposta em Frequência (FRF) (GAJDÀSTY, 2011). O método de análise de caminhos de transmissão, que pode ser referenciado na literatura também como TPA (Transfer Path Analysis), SPC (Sound Path Contribution) e NPA (Noise Path Analysis), permite individualizar as contribuições das fontes de ruído e vibração e dos caminhos de transmissão por vias aérea e estrutural (MOURA, 2016). 
As Funções de Resposta em Frequência caracterizam uma trajetória através de relações entre grandezas físicas de dois pontos. A entrada ou início da trajetória pode ser entendida como o estímulo ao sistema. A saída ou final da trajetória pode ser considerada como a resposta do sistema ao estímulo aplicado. A FRF é a razão entre o sinal de saída e o sinal de entrada no domínio da frequência. A Figura 3 demonstra um esquema da FRF.

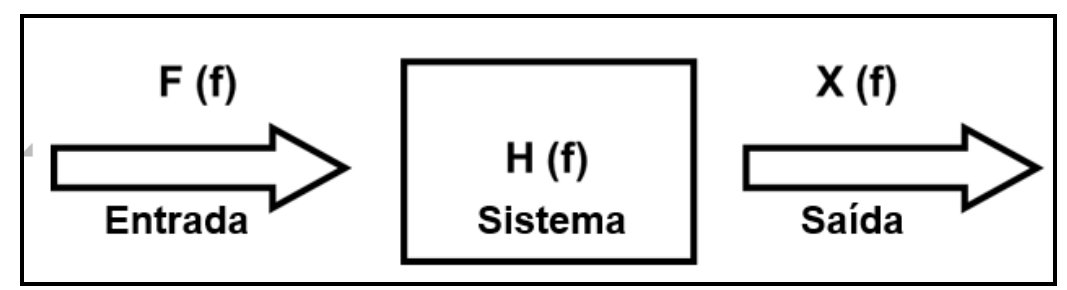

Figura 3 - Esquema de Função de Resposta em Frequência Fonte: Dos autores (2018).

As equações 1 e 2 demonstram o cálculo da FRF.

$$
\begin{gathered}
F(f) \times H(f)=X(f) \\
H(f)=\frac{X(f)}{F(f)}
\end{gathered}
$$

Onde $H(f)$ é a função de resposta em frequência, $X(f)$ o sinal de saída no domínio da frequência e $F(f)$ o sinal de entrada no domínio da frequência (GUIMARÃES, 2008).

A função de Coerência é uma grandeza que relaciona os sinais de entrada e saída e pode ser interpretada como sendo a fração do espectro de saída que é proveniente do espectro de entrada. A função, para cada valor de frequência, assume o valor zero quando não existe relação entre os sinais de entrada e saída e assume valor 1 quando a saída é totalmente correlacionada à entrada. A função coerência $\left(\gamma_{x y}^{2}\right)$ é definida como:

$$
\gamma_{x y}^{2}(f)=\frac{G_{x y}(f)^{2}}{G_{x x}(f) \cdot G_{y y}(f)}
$$

Onde $G_{x y}$ é o espectro cruzado entre os sinais de entrada e saída e $G_{x x}$ e $G_{y y}$ os autoespectros dos sinais de entrada e saída, respectivamente (GUIMARÃES, 2008).

As trajetórias de transferência vibroacústicas são Funções de Resposta em Frequência que descrevem trajetórias que têm origem na vibração da estrutura. Já a resposta refere-se a um ponto localizado no espaço envolvido por ar. A partir da aplicação de uma força na estrutura em algum ponto determinado, essa irradia energia sonora que é transmitida pelo ar até o ponto do receptor.É 
denominada como uma trajetória híbrida que tem um estímulo na estrutura e resposta observada em algum ponto do habitáculo do veículo, determinando assim, o ruído transmitido por via estrutural. A Figura 4 demonstra a determinação do ruído estrutural.

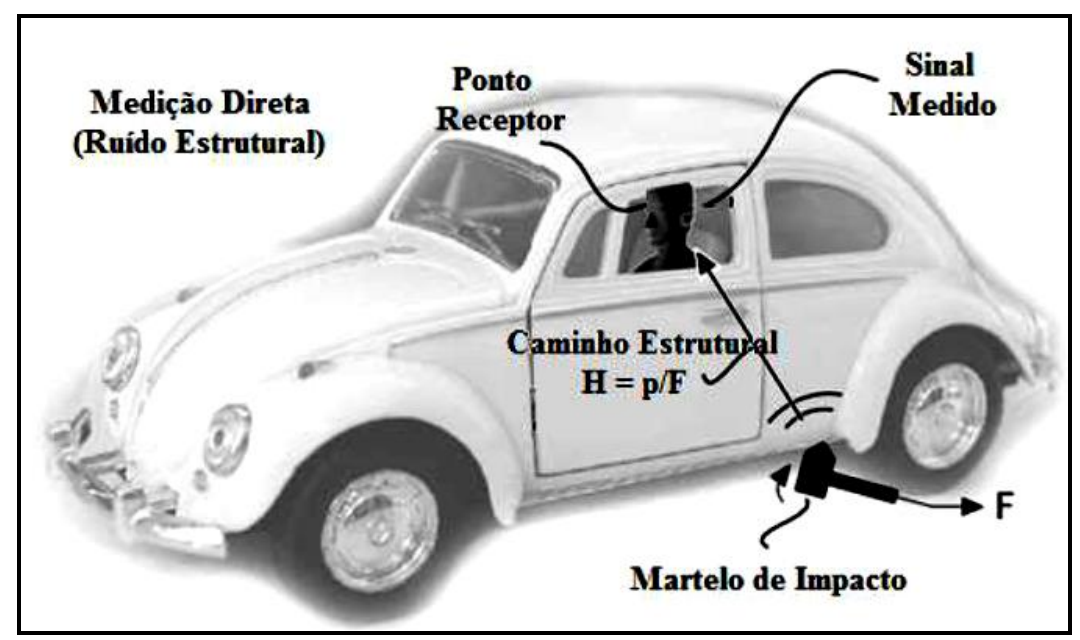

Figura 4 - Medição de caminhos de transmissão via estrutura Fonte: Vorlander (2008).

\subsection{Absorção Sonora}

A absorção sonora é amplamente utilizada para redução de ruído em veículos e são aplicados no interior do habitáculo, no compartimento do motor, e até mesmo no exterior de veículos (VIGÈ, 2010). A atenuação do ruído se dá, pincipalmente, pela perda de energia sonora através do atrito, no qual as partículas de ar ao encontrar um material absorvente são submetidas a fenômenos de fricção através da interação com os poros ou fibras desse material. Os materiais para absorção sonora são, normalmente, porosos ou fibrosos. Para que o material tenha eficiência, é fundamental que se permita o fluxo de ar no meio absorvente e, consequentemente, a propagação da onda (BISTAFA, 2011).

Os materiais porosos utilizados como absorvedores sonoros podem ser do tipo celular, fibroso ou granular, conforme ilustrado na Figura 5. As características acústicas são dadas pela composição, orientação e dimensão das fibras, bem como pela densidade e pela forma como as fibras são interconectadas (MAREZE, 2013). 


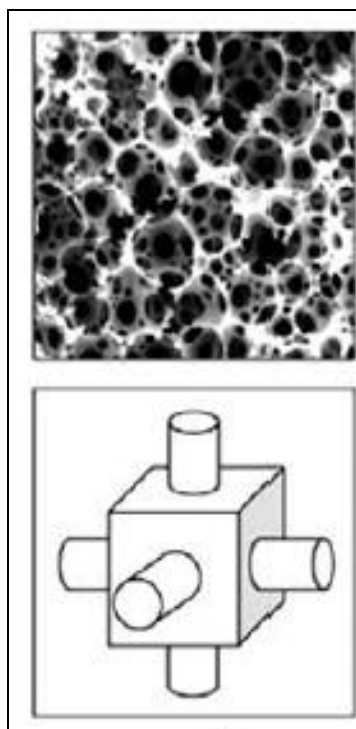

(a)
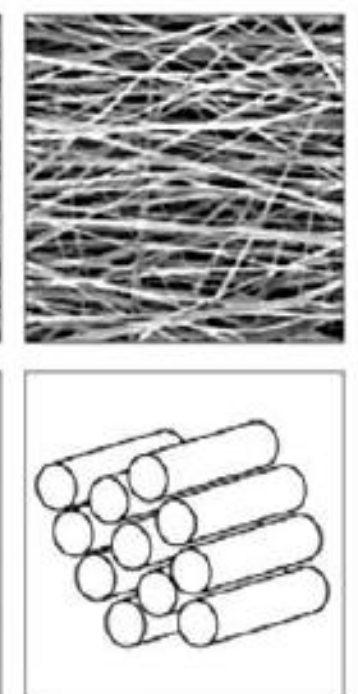

(b)
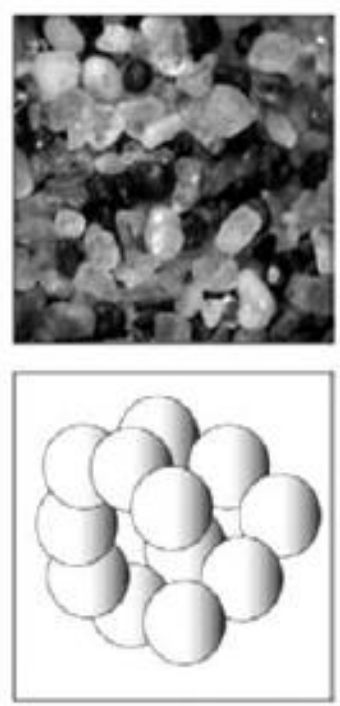

(c)

Figura 5 - Tipos de estrutura de materiais porosos típicos: celulares (a), fibrosos (b) e granulares (c) Fonte: Mareze (2013).

O coeficiente de absorção sonora ( $\alpha$ ) de um material é uma característica que determina seu desempenho quanto à capacidade de absorver ruídos por faixa de frequência. O coeficiente é determinado experimentalmente através de ensaios normalizados e seu valor varia de zero a 1 (um). Quanto mais próximo de 1 (um) for o valor do coeficiente de absorção, melhor será sua absorção sonora (BISTAFA, 2011).

Um material poroso é significativamente mais eficaz a partir da faixa de frequência de $1000 \mathrm{~Hz}$, quanto à absorção do som. Devido a este comportamento, seu emprego é basicamente para tratamento de ruído aéreo. O gráfico da Figura 6 apresenta uma curva típica de coeficiente de absorção sonora $(\alpha)$ em função da frequência, de materiais absorventes de som porosos e fibrosos instalados sobre superfície sólida.

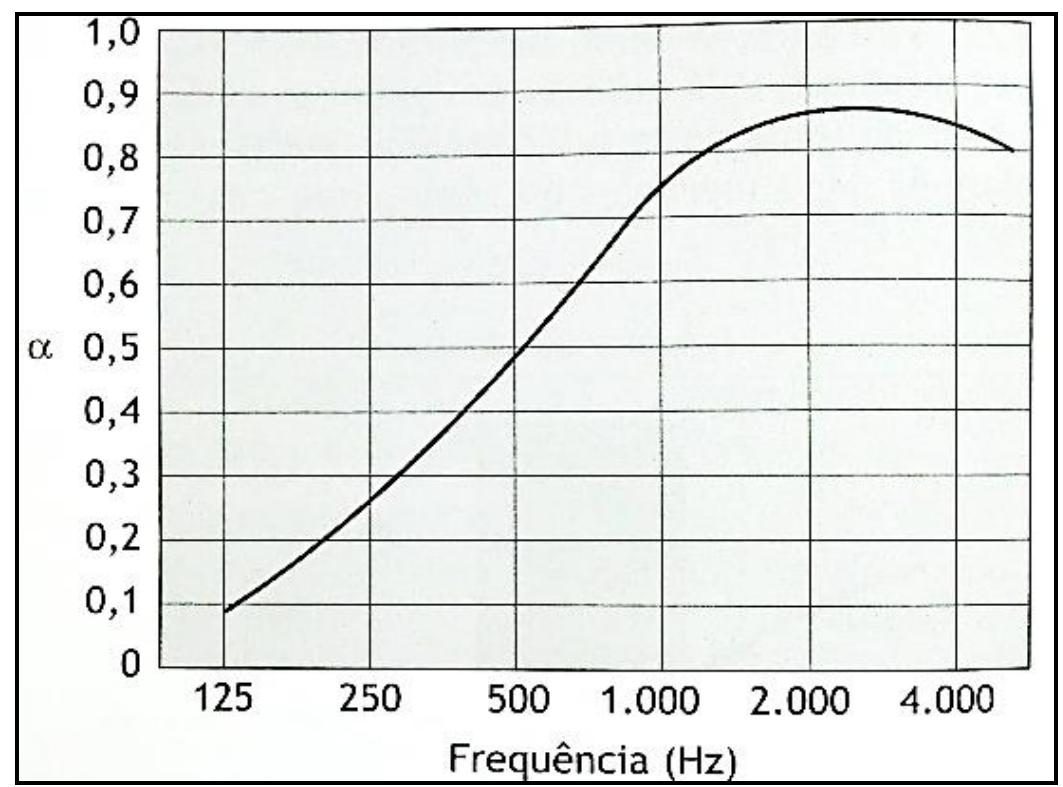

Figura 6 - Gráfico típico de absorção sonora para materiais absorventes de som porosos/fibrosos

Fonte: Bistafa (2011). 


\section{MATERIAIS E MÉTODOS}

\subsection{Protótipo da carroceria}

Para o desenvolvimento do trabalho foi construído um protótipo de carroceria de um automóvel, com dimensões aproximadas do habitáculo de um modelo hatch pequeno. A estrutura da carroceria é composta por tubos quadrados de aço soldados entre si. Os tubos que formam a estrutura externa da carroceria, denominada estrutura principal, possuem maiores dimensões que os tubos da estrutura secundária, conforme ilustra a Figura 7.

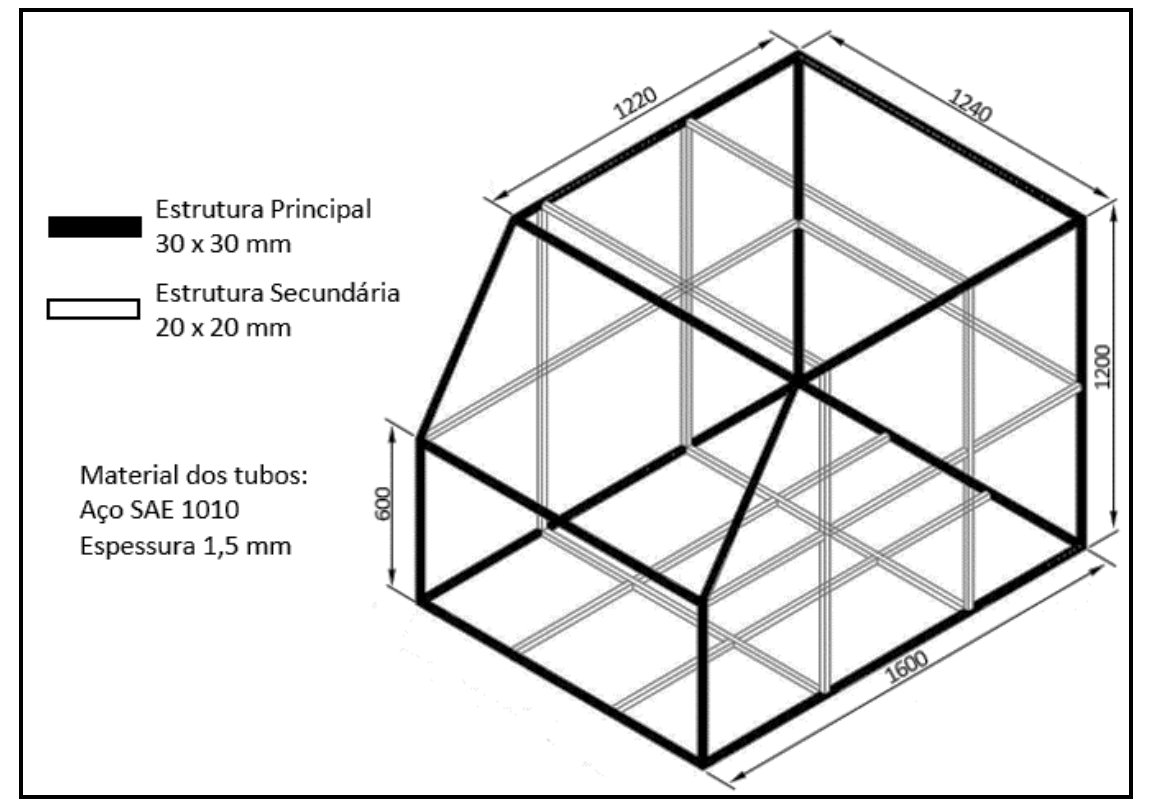

Figura 7 - Estrutura tubular do protótipo da carroceria Fonte: Dos autores (2018).

A carroceria é fechada com chapas de aço SAE 1010 de 0,910 mm de espessura através de rebites, vedadas com silicone, exceto na parte lateral esquerda dianteira, que é aparafusada para permitir o acesso ao seu interior, conforme Figura 8.

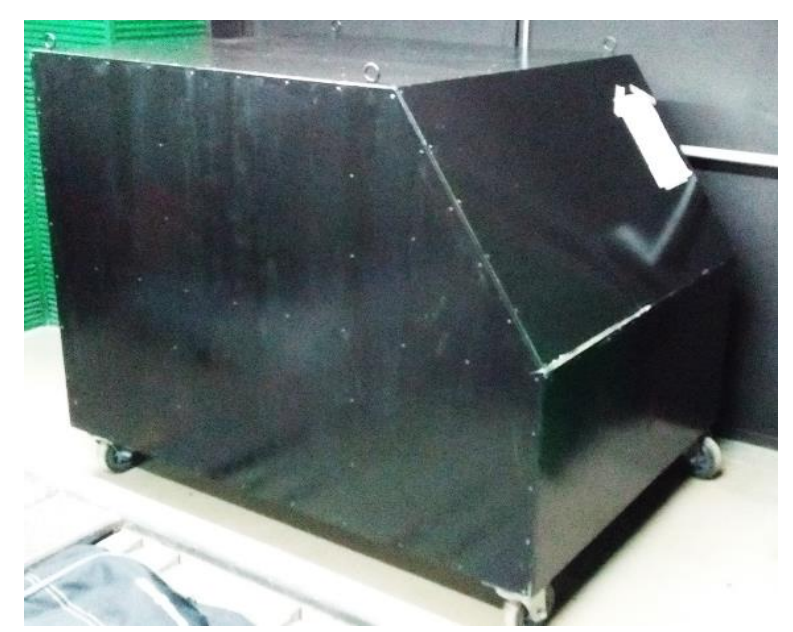

Figura 8 - Protótipo da carroceria com chapas Fonte: Dos autores (2018) 


\subsection{Testes experimentais}

Os testes experimentais para o desenvolvimento da metodologia consistem em medições de Funções de Resposta em Frequência vibroacústica do protótipo da carroceria, com excitação na estrutura e resposta no interior do habitáculo. A excitação é realizada através de um martelo de impacto com um transdutor de força e a resposta é medida através de um microfone posicionado na região da orelha direita do motorista. A Figura 7 ilustra o modelo do sistema de análise da FRF.

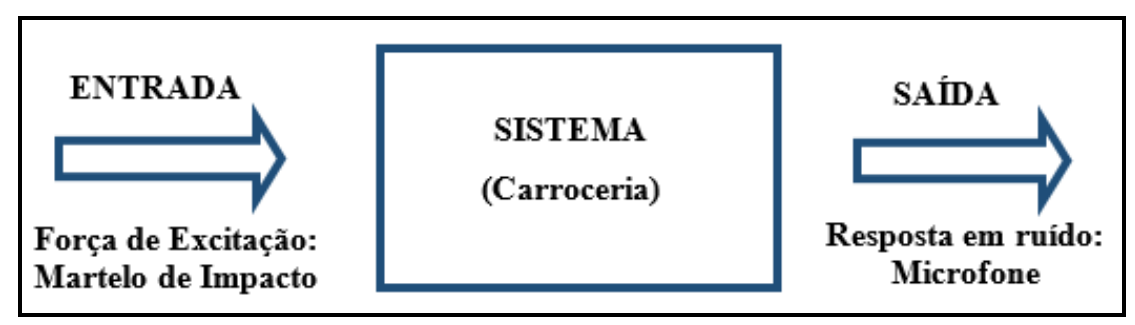

Figura 9 - Modelo do sistema de análise Fonte: Dos autores (2018).

O ponto de excitação na carroceria foi definido na região dianteira inferior esquerda e foi determinado considerando que é um ponto rígido da estrutura e região de importantes fontes de ruído estrutural, tais como suspensão e conjunto motopropulsor. O ponto da resposta foi definido como a região da orelha direita do motorista, seguindo procedimentos adotados por montadoras de automóveis (FIAT AUTO, 2004). A Figura 10 ilustra os pontos de medição.

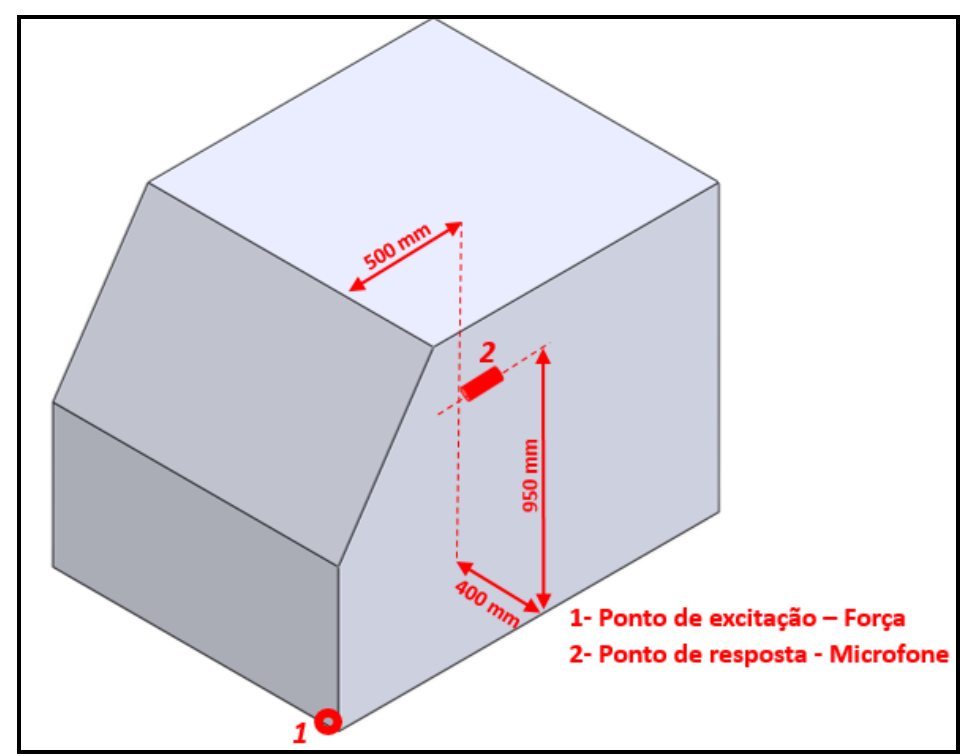

Figura 10 - Posicionamento dos pontos de excitação e resposta Fonte: Dos autores (2018).

Os equipamentos utilizados para a realização dos testes e análises dos resultados estão descritos na Tabela 1. 
Tabela 1 - Equipamentos utilizados para testes e análises

\begin{tabular}{ccc}
\hline Equipamentos & Especificação & Fabricante \\
\hline Software & TestLab versão 15 & LMS Siemens \\
Analisador & Scadas Mobile 8 canais & LMS Siemens \\
Microfone & $1 / 2 ”$ campo livre, $50 \mathrm{mV} / \mathrm{Pa}$, mod. 46 AE & GRAS \\
Martelo de impacto & $2,25 \mathrm{mV} / \mathrm{N}$, mod. $086 \mathrm{C} 03$ & PCB \\
\hline
\end{tabular}

Fonte: Dos autores (2018).

\subsection{Configurações dos testes}

Para validação dos resultados do procedimento desenvolvido, os testes foram realizados em duas configurações, sendo a primeira com a carroceria sem isolamentos e a segunda com a carroceria com isolamentos aplicados no pavimento, na parede corta fogo e no teto. Os isolamentos consistem em mantas de material poroso de fibra têxtil de aplicação automotiva com gramatura $1200 \mathrm{~g} / \mathrm{m}^{2}$, do fabricante Adler PTI, conforme ilustrado na Figura 11.

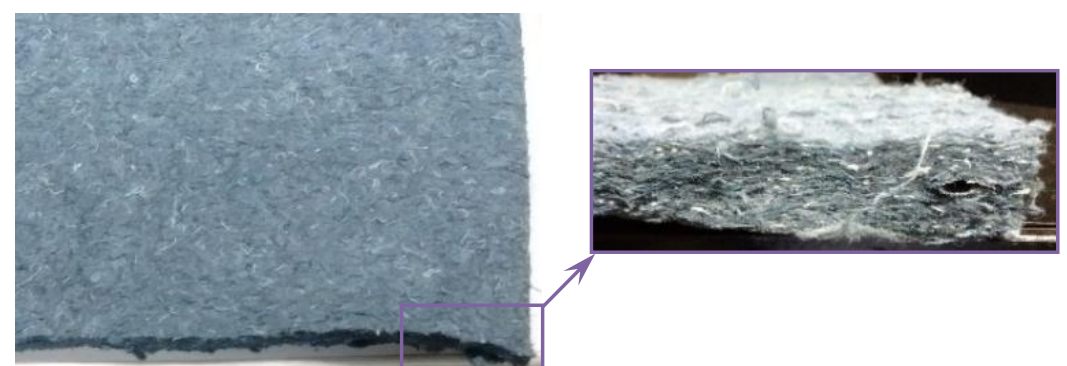

Figura 11 - Manta de isolamento poroso de fibra têxtil, gramatura $1200 \mathrm{~g} / \mathrm{m}^{2}$ Fonte: Dos autores (2018).

A Figura 12 demonstra a carroceria com os isolamentos aplicados nas regiões do pavimento, parede corta fogo e teto.

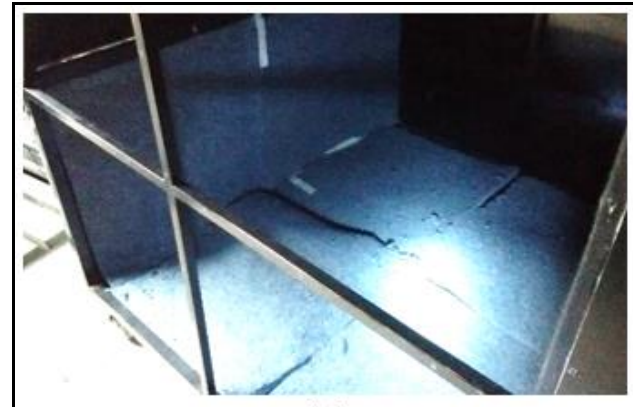

(a)

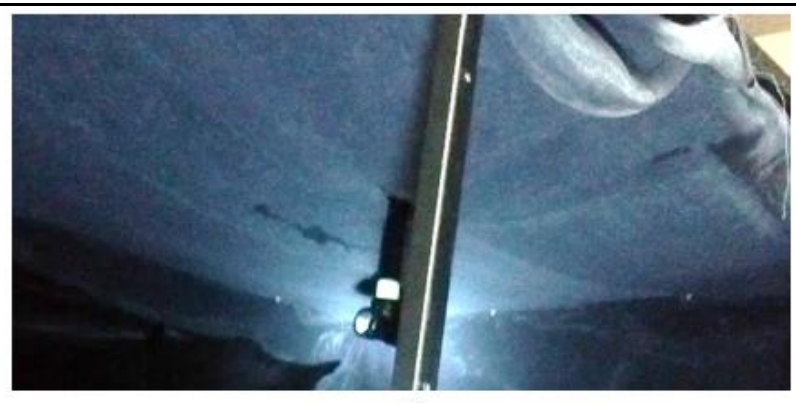

(b)

Figura 12 - Aplicação dos isolamentos porosos na carroceria: pavimento e parede corta fogo (a) e teto (b) Fonte: Dos autores (2018).

A área aplicada de isolamentos é de 4,24 $\mathrm{m}^{2}$ e a massa total dos isolamentos é de $5,0 \mathrm{~kg}$. 


\section{RESULTADOS}

Foram obtidas as funções de resposta em frequência (FRF) para cada configuração testada. As FRFs obtidas são as funções de sensibilidade vibroacústica. Os valores mais elevados da função sensibilidade vibroacústica indicam que a carroceria responde com maior intensidade a uma excitação naquela frequência. Desta forma, quanto maior o valor da sensibilidade, pior será o comportamento acústico da carroceria para uma excitação estrutural. No gráfico da Figura 13 é apresentado o resultado para a carroceria sem isolamentos.

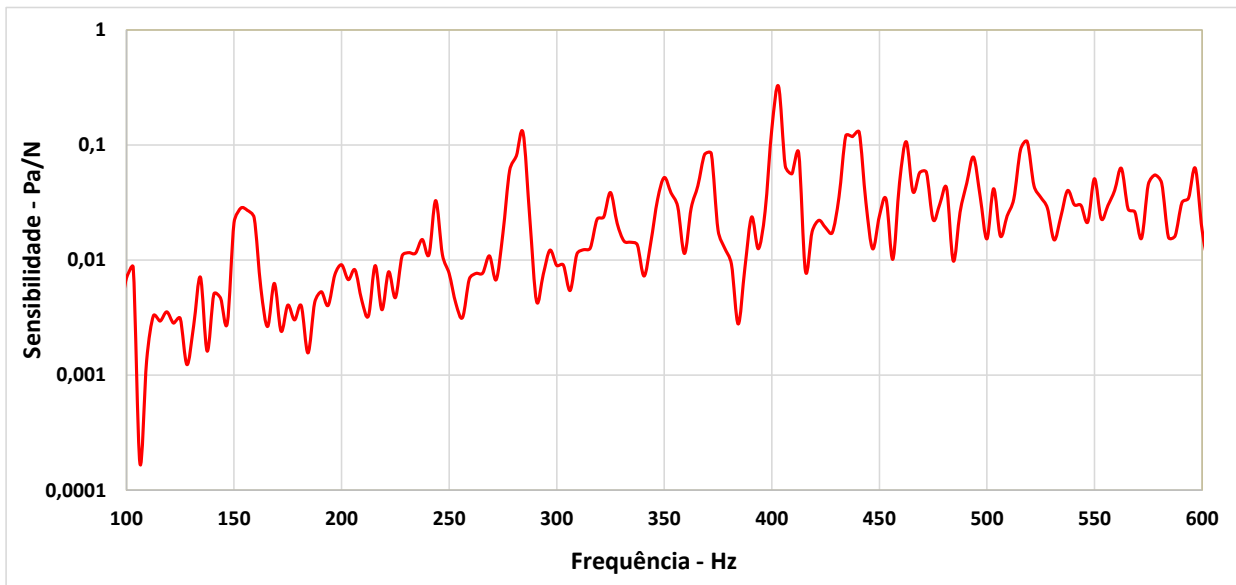

Figura 13 - Gráfico da Função sensibilidade vibroacústica da carroceria Fonte: Dos autores (2018).

Os resultados apresentados no gráfico da Figura 13 demonstram a ocorrência de picos de valores de sensibilidade em toda a faixa de frequência analisada.

No gráfico da Figura 14 são apresentados os resultados comparativos entre a carroceria sem isolamento e com isolamentos de $1200 \mathrm{~g} / \mathrm{m}^{2}$ aplicados.

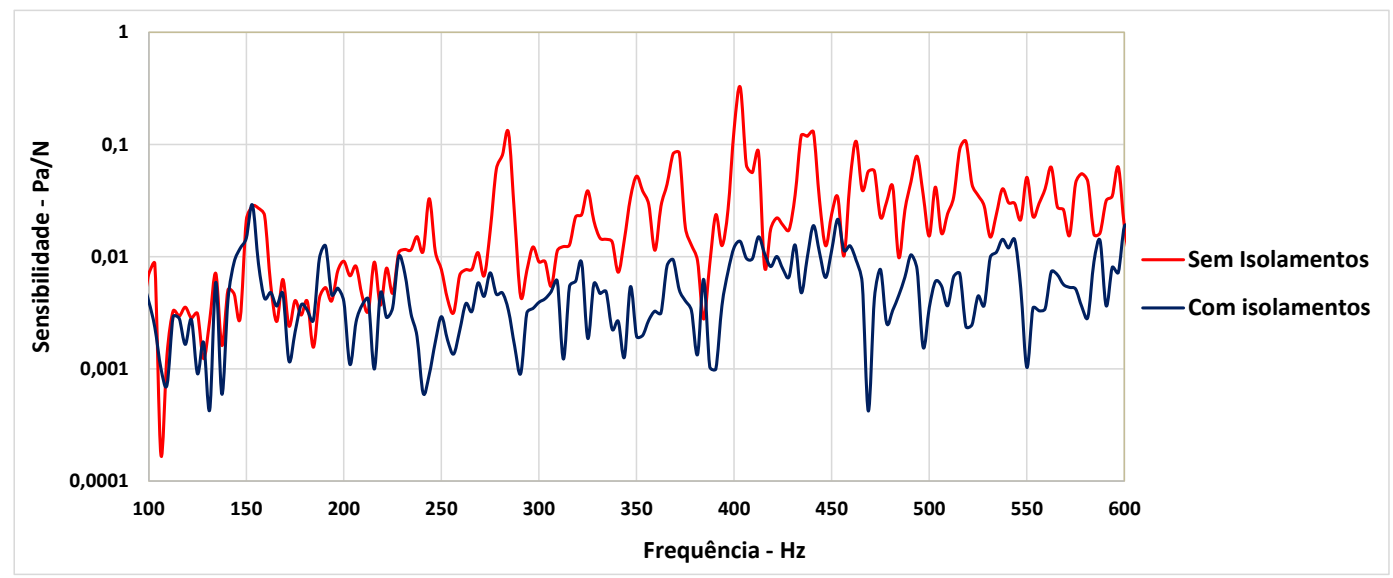

Figura 14 - Gráfico comparativo da Função sensibilidade vibroacústica da carroceria com e sem isolamentos

Fonte: Dos autores (2018).

Os resultados apresentados no gráfico comparativo da Figura 14 demonstram que ocorreu significativa atenuação da sensibilidade vibroacústica com a aplicação de isolamentos na carroceria, principalmente nas seguintes faixas de frequência: $200 \mathrm{~Hz}, 240 \mathrm{~Hz}, 280 \mathrm{~Hz}, 320$ a 380 
Hz, 390 a 420 Hz, 430 a $440 \mathrm{~Hz}$ e 460 a 580 Hz. A Tabela 2 apresenta a porcentagem de redução da sensibilidade vibroacústica nas frequências mais significativas, com a aplicação de isolamentos.

Tabela 2 - Atenuação de ruído estrutural entre carroceria sem isolamentos e com isolamentos

\begin{tabular}{cccc}
\hline $\begin{array}{c}\text { Frequência } \\
{[\mathbf{H z}]}\end{array}$ & \multicolumn{2}{c}{ Sensibilidade [Pa/N] } & Atenuação \\
\hline 200 & 0,00910 & 0,00224 & $\mathbf{7 5} \%$ \\
240 & 0,01114 & 0,00114 & $\mathbf{9 0} \%$ \\
285 & 0,12739 & 0,00391 & $\mathbf{9 7} \%$ \\
350 & 0,03841 & 0,00157 & $\mathbf{9 6} \%$ \\
400 & 0,32338 & 0,01853 & $\mathbf{9 4} \%$ \\
440 & 0,12920 & 0,01424 & $\mathbf{8 9} \%$ \\
500 & 0,07842 & 0,00828 & $\mathbf{8 9} \%$ \\
520 & 0,10673 & 0,00274 & $\mathbf{9 7} \%$ \\
550 & 0,04015 & 0,00685 & $\mathbf{9 4} \%$ \\
580 & 0,06263 & 0,00560 & $\mathbf{9 3} \%$ \\
\hline
\end{tabular}

Fonte: Dos autores (2018).

A redução da sensibilidade vibroacústica indica que o habitáculo apresentará um nível de ruído mais baixo quando for submetido a excitações estruturais. Dessa forma, a aplicação de mantas de isolamentos porosos contribui de forma bastante significativa para a redução de ruído estrutural interno, conforme demonstrado na Tabela 2.

Foram realizadas ainda as análises da função coerência de cada configuração para verificar a relação entre o sinal de entrada e o sinal de saída. Nas duas configurações testadas os valores de coerência apresentaram valores acima de 0,9 em toda a faixa de frequência analisada, portanto, considerado satisfatório.

Ressalta-se que a metodologia desenvolvida para avaliação de atenuação de ruído estrutural em habitáculo de automóvel permitirá a realização de testes de quaisquer tipos de isolamentos acústicos, sejam eles testes comparativos entre tecnologias de materiais, entre diferentes características ou parâmetros técnicos, composição de diferentes materiais, e ainda, testes de posicionamento de isolamentos, entre outros. Dessa forma, a utilização dessa metodologia proporcionará um ganho de tempo e custo de avaliação, se comparada à realização de testes utilizando um veículo.

\section{CONCLUSÃO}

A partir dos resultados apresentados neste trabalho, conclui-se que o desenvolvimento da metodologia para avaliação de atenuação ruído estrutural em automóveis é considerado válido e uma boa alternativa para redução de tempo e custo de testes, análises e respostas no desenvolvimento de propostas para melhoria de ruído interno. 
Destaca-se que a atenuação sonora na faixa de médias frequências contribui para a melhoria da sensação de aspereza (harshness), faixa na qual atuam fontes sonoras importantes como o motopropulsor e conjunto de rodas e suspensão. Portanto, a aplicação dessa metodologia para desenvolvimento de propostas de atenuação de ruído estrutural, poderá contribuir de forma significativa no trabalho de refinamento de conforto acústico em automóveis realizados pelos engenheiros das montadoras e das fornecedoras de peças.

Deve-se ressaltar que materiais para absorção sonora são leves, de custo relativamente baixo e demandam pouco tempo de construção de ferramental para sua produção, o que pode tornar viável a implementação em um veículo mesmo em curto espaço de tempo. Considera-se ainda que este tipo de material tem pouca influência no comportamento dinâmico de um automóvel, não modificando consideravelmente seu peso e, desta forma, não influenciando no consumo de combustível. Porém, cabe à montadora realizar todos os levantamentos e analisar a viabilidade para cada caso, considerando o efeito positivo quanto à melhoria do conforto acústico e confrontando com o comportamento dinâmico, tempo de desenvolvimento e custos.

Finalmente, a partir da metodologia desenvolvida, propõem-se como próximos trabalhos a avaliação de diferentes tipos de isolamentos e/ou regiões de aplicação, dimensões e quantidade, a fim de se criar um banco de dados para futuras consultas.

\title{
DEVELOPMENT OF EXPERIMENTAL METHODOLOGY FOR EVALUATION OF STRUCTURE-BORNE NOISE ATENUATION THROUGH SOUND ABSORPTION IN AUTOMOBILES
}

\begin{abstract}
This work deals with the development of a methodology to evaluate the attenuation of the noise transmitted by the structural route to the passenger compartment of a car through the application of material for sound absorption. The solutions for structure-borne noise attenuation are generally more complex to implement and require more time and cost as they have different links to other vehicle performance requirements as they are related to modifications that may include the structure, supports or mounts. Sound absorbing materials are used in automobiles with the aim of attenuating high frequency noise due to their characteristics. This study proposes the use of this type of material to attenuate noise of low and medium frequencies, predominant in structural noise, complementing the existing ones, in order to refine the vibroacoustic behavior of the vehicle. For the development of the methodology a steel prototype of a passenger compartment car was built and tests of Vibroacoustics Frequency Response Function. For validation of the methodology, tests were performed with and without sound absorbing blankets. It was observed in the tests performed that the application of sound absorption material significantly attenuates the structure-borne noise in the range of medium frequencies and that the developed methodology can help in the development of new proposals, comparative tests of materials, positioning and region of application of the blankets, contributing in the reduction of the time of development of solutions of proposals for refinement of the acoustic comfort in vehicles.
\end{abstract}

Keywords: Structure borne noise. Acoustic comfort. Sound absorption. FRF. 


\section{REFERÊNCIAS}

BISTAFA, Sylvio R. Acústica aplicada ao controle de ruído. 2. ed. rev. São Paulo: Blucher, 2011.

FIAT AUTO. Performance Standard N.7- R0151: vehicle and shell: acoustic and vibration Transfer Functions Analysis. Satiz-Normazione, 2004.

GADJDÀTSY, P. A. Advanced transfer path analysis methods. 2011. 208 f. Doctoral Dissertation - Faculteit Toegepaste Wetenschappen, Katholieke Universiteit Leuven, Leuven, 2011.

GERGES, Samir N. Y. Ruído e vibrações veiculares. NR Editora, Consultoria e Treinamento: Florianópolis, 2005.

GERGES, Samir N. Y. Ruído: fundamentos e controle. 2. ed. Florianópolis: NR Editora, 2000.

GOETCHIUS, G. M. Body structure noise and vibration refinement. In: WANG, X. Vehicle noise and vibration refinement. Cambridge: Woodhead Publishing Limited, 2010. cap. 15, p. $351-386$

GUIMARÃES, Gustavo Paulinelli. Desenvolvimento de análise por trajetórias vibroacústicas para aplicação automotiva. 2008. 121 f. Dissertação (Mestrado) - Programa de Pós-Graduação em Engenharia Mecânica, Universidade Federal de Minas Gerais, Belo Horizonte, 2008.

HARRISON, M. Vehicle refinement: controlling noise and vibration in road vehicles. Burlington: Elsevier Butterworth-Heinemann, 2004.

KINSLER, Lawrence E. et al. Fundamentals of acoustics. 4. ed. New York: John Wiley \& Sons, Inc., 2000.

MAREZE, P.H. Análise da influência da microgeometria na absorção sonora de materiais porosos de estrutura rígida. 2013. 285 f. Tese (Doutorado) - Programa de Pós-Graduação em Engenharia Mecânica, Universidade Federal de Santa Catarina, Florianópolis, 2013.

MOURA, Frederico Luiz de Carvalho. Avaliação de métodos inversos para estimativa de forças operacionais de veículos em acústica e vibrações. 2016. 105 f. Dissertação (Mestrado) Programa de Pós-Graduação em Engenharia de Estruturas, Universidade Federal de Minas Gerais, Belo Horizonte, 2016.

VECCI, M. A. M. Ruído ambiental. Belo Horizonte: Universidade Federal de Minas Gerais, 2004.

VIGÈ, Davide. Cabin sound package design and development. In: WANG, Xu. Vehicle noise and vibration refinement. Cambridge: Woodhead Publishing Limited, 2010. cap. 13, p. 286317.

VORLANDER, M. Auralization: fundamentals of acoustics, modelling, simulation, algorithms and acoustic virtual reality. Berlin: Springer, 2008. 
WANG, Xu. Vehicle noise and vibration refinement. Cambridge: Woodhead Publishing Limited, 2010.

\title{
AGRADECIMENTOS
}

O presente trabalho foi realizado com o apoio da Coordenação de Aperfeiçoamento de Pessoal de Nível Superior - Brasil (CAPES) - código de financiamento 001. Os autores agradecem ainda o suporte da PUC Minas (Pontifícia Universidade Católica de Minas Gerais) e das empresas Adler PTI e Fiat Chrysler Automobiles para a realização deste trabalho.

\section{DADOS DOS AUTORES:}

\author{
Rogério Gondim Costa \\ E-mail: rogeriogondim@gmail.com \\ Currículo lattes: http://lattes.cnpq.br/6840690220514757 \\ Doutor em Engenharia Mecânica em curso na Pontifícia Universidade Católica de Minas Gerais. \\ Mestre em Engenharia Mecânica com ênfase em Acústica e Vibrações pela Universidade Federal \\ de Santa Catarina (UFSC). Especialista em Engenharia de Segurança do Trabalho pela \\ Universidade Candido Mendes. Graduado em Engenharia Mecânica pelo Centro Federal de \\ Educação Tecnológica de Minas Gerais (CEFET-MG). Atualmente é professor do curso de \\ Engenharia Mecânica na Faculdade Pitágoras.
}

\section{Claysson Bruno Santos Vimieiro \\ E-mail: claysson@pucminas.br \\ Currículo lattes: http://lattes.cnpq.br/0149542794493944}

Pós-Doutor na área de Propriedade Intelectual. Doutor em Engenharia Mecânica pela Universidade Federal de Minas Gerais (2008), com período de doutorado sanduíche na Universidade Técnica de Ilmenau (Technische Universität Ilmenau) na Alemanha. Mestre em Engenharia Mecânica pela Universidade Federal de Minas Gerais (2004). Graduado em Engenharia Mecânica pela Universidade Federal de Minas Gerais (2001). Atualmente é professor adjunto do Departamento de Engenharia Mecânica da PUC-Minas e docente permanente do Programa de Pós-graduação em Engenharia Mecânica da PUC-Minas. Também é professor Associado do Departamento de Engenharia Mecânica da UFMG e docente permanente do Programa de Pós-graduação em Engenharia Mecânica da UFMG.

\section{Tiago Simão Ferreira}

E-mail: tiago.simao@ifmg.edu.br

Currículo lattes: http://lattes.cnpq.br/8613417647281145

Doutor em Engenharia Mecânica pela Puc-Minas. Mestre em Engenharia Mecânica pela PucMinas. Graduado em Engenharia Mecânica pela Universidade Federal de Minas Gerais. Atualmente é professor com dedicação exclusiva e coordenador de pesquisa do Instituto Federal de Minas Gerais - Santa Luzia. 